\title{
Analisis pengaruh economic value added (EVA), capital structure, total assets turnover dan current ratio terhadap kinerja keuangan pada perusahaan sektor industri dasar dan kimia yang terdaftar di BEI pada Tahun 2017-2019
}

\section{Joey Rizky Lombogia; Yois Nelsari Malau*; Faradiva Rosadi; Angel Grace Monica N}

Prodi Akuntansi, Fakultas Ekonomi, Universitas Prima Indonesia, Medan

*E-mail korespondensi : yoisnelsarimalau@gmail.com

\begin{abstract}
This presentation intends to analyze and assess the effect of economic value-added, capital structure, total assets turnover, and current ratio on financial performance. The sample is 39, multiplied by three years, so that the number of observations is 117. The techniques and data used are a purposive sampling of the IDX financial statements from the 2017-2019 period. Partially the economic value-added, capital structure, current ratio are not significant. There is no significant effect while TATO has a substantial impact on financial performance in manufacturing companies in 2017-2019. It can be concluded that EVA and DER CR have no considerable effect while TATO was a significant influence in 2017-2019.
\end{abstract}

Keywords: EVA, CS, TATO, CR, ROA.

\begin{abstract}
Abstrak
Penyajian ini bermaksud untuk menganalisa dan menilai tentang pengaruh economic value added, capital structure, total assets turnover, dan current ratio terhadap Kinerja Keuangan. Sampel sebanyak 39, dikalikan 3 tahun sehingga jumlah observasi sebanyak 117 , teknik dan data yang digunakan purposive sampling laporan keuangan BEI dari periode 2017-2019. Secara partial economie value added, capital structure, current ratio tidak signifikan dan tidak adanya pengaruh sementara TATO berpengaruh signifikan dengan kinerja keuangan di perusahaan manufaktur dalam tahun 2017-2019 dan secara simultan dapat disimpulkan bahwa EVA, DER CR tidak ada pengaruh yang signifikan sementara TATO adanya pengaruh yang signifikan pada tahun 20I7-2019.
\end{abstract}

Kata kunci : EVA, CS , TATO, CR, ROA.

\section{PENDAHULUAN}

Pada kegiatan operasi pasti rnembutuhkan sebuah dana untuk modal awal. Modal tersebut dapat berupa aset sendiri ataupun dana eksternal semacam pinjarnan dari bank atau penanaman saham dari investor dan pastinya investor akan menyeleksi perusahaan yang mempunyai perkembangan laba naik secara signifikan. Satu diantara sektor di Bursa Efek lndonesia yang dapat menarik para investor adalah Industri Dasar dan Kimia. lndustri Dasar dan Kimia adalah mencakup perubahan semua bahan organik dan bahan non organik dengan melalui proses kimia dan pembentukan sebuah produk. 
Sesuai dengan tahun 2019, lndeks sektor industri dasar \& kimia tercatat di BEl 8,72\% data tahun ini alias sebagai sektor yang memiliki kemajuan yang sangat cepat. Sektor industri dasar \& kimia sedangmeningkat lagi begitu indeks harga saham gabungan (QC) terkoreksi $2,95 \%$ year to date. Untuk menakar suatu kinerja keuangan di satu perusahaan bisa ditemukan dengan banyak cara, dapat dilihat dengan ciri-ciri adanya perputaran aset untuk menciptakan laba dengan memakai rasio return on asset (ROA). Dalam menghasilkan laba, tentunya harus mempertimbangkan suatu harap para penyedia dana, beberapa harapan pemilik dana dalam hal rnenghasilkan laba. Dalam hal ini perusahaan dapat menggunakan economic value added agar lebih baik lagi. Memperkirakan sampai dimana kapasitas perusahaan melunasi kewajiban jangka waktu pendek dan jangka waktu panjangnya tentunya dengan mengukur kinerja perusahaan. Perusahaan dapat mengetahui kemampuan setiap rupiah modal pribadi perusahaan yang digunakan untuk jaminan utang.

Kinerja keuangan di suatu perusahaan dapat dikelola dengan menggunakan asset perusahaan seperti total assets turnover (perputaran total aset). Pengukuran seberapa besar total aktiva suatu perusahaan untuk menghasilkan pendapatan semakin tinggi maka semakin efisiensi. Kemampuan dalam membayar utang jangka pendek suatu perusahaan dapat digunakan dengan current ratio. Dengan rnenggunakan rasio ini dapat diketahui bagaimana kinerja perusahaan dalam membayar utang dengan asset lancar. Peneliti Ratih, Dzulkirom, dan Saifi (2014) dengan itu penelitian ini menegaskan perhitungan nilai EVA adanya pengaruh penting terhadap kinerja keuangan. Tinggnya nilai EVA sudah otomatis menaikkan nilai perusahaan.

Peneliti Arizca dan Farida (2015) menjelaskan bahwa adanya hubungan positif komposisi modal pada aktivitas, terhadap likuiditas adanya hubungan negatif tidak signifikan dan profitabilitas adanya hubungan negatif yang signifikan sedangkan terhadap nilai pasar tidak memiliki pengaruh. Peneliti Rachmat R.M (2017) bahwa TATO sangat penting dalam ROA. Peneliti Desy Anggareni (2015) berjudul "Pengaruh $\mathrm{CR}, \mathrm{QR}, \mathrm{DER}$ dan standard perusahaan dalam kinerja perusahaan yang rnenyatakan bahwa signifikan terhadap kinerja keuangan.

\section{TINJAUAN PUSTAKA}

\section{Pengaruh economic value added terhadap kinerja keuangan}

Menurut Tunggal (Endang, 2016:35) apabila perusahaan memiliki EVA posit if maka dapat memberi nilai tambah keperusahaannya. Menurut Ismail (2011) semakin tinggi EVA maka memberikan dampak yang positif dan penambahkan nilai perusahaan. Jurnal yang ditulis oleh S. Heri Winarno tahun 2014 dimana kurang baik nilai dari EVA bersifat negatif, begitu juga sebaliknya baik apabila EVA bersifat positif. Menurut pendapat lain yang tentunya sudah diteliti seperti menurut Sugiharto bahwasannya perubahan EVA akan menurunkan nilai ROA. Dan jikalau ada peningkatan EVA sebesar 1,000 dan itu akan menaikkan ROE. Jika ada peningkatan ROE sebesar 1,000 maka juga akan meningkatkan ROA.

\section{Pengaruh capital structure terhadap kinerja keuangan}

Menurut Kusumaja (2011) terdapat sifat positif dalam capital structure terhadap nilai perusahaan. Menurut Ruspandi \& Asma (2014) menyatakan hasil bahwa tidak adanya pengaruh signifikan DER kepada ROA tetapi tidak untuk ROE. Kusurnajaya 
(2011) menyatakan bahwa adanya pengaruh positif struktur modal perusahaan dalam hutang panjang, meningkatnya ataupun menurunnya sangat berhubungan dengan nilai laba bersih, yang akan mempengaruhi pendapatan laba untuk membayar semua kewajibannya. Menurut jurnal sebelumnya yang sudah diteliti oleh Achinad Koinara Tahun 2016 memberikan kesimpulan bahwa adanya signifikan perubahan struktur modal, DAR atau DER terhadap kinerja keuangan menggunakan rasio profitabilitas berupa return on asset dan return on equity.

\section{Pengaruh total aseets turnover terhadap kinerja keuangan}

Pendapat Kasmir (2012:203) mengungkapkan rendahnya ROA disebabkan margin laba yang juga rendah karena perputaran aktiva rendah.Penelitian Rachmat Rizky Muchlis (2017) menyatakan bahwa TATO sangat penting bagi ROA. Jadi TATO sangat mempengaruhi nilai ROA. Adanya yang signifikan TATO dan CR pada ROA. Menurut Kasmir (2017:188) jika memiliki perputaran total aktiva minimal 2 kali atau lebih dalam standar industry maka perusahaan tersebut perusahaan baik. Menurut peneliti sebelumnya oleh Alpi dan Gunawan dalam jurnal tahun 2015 bahwa adanya pengaruh penting CR dan TATO pada ROA.

\section{Pengaruh current ratio terhadap kinerja keuangan}

Bagi peneliti Liani (2015), current ratio berpengaruh signifikan dengan arah positif terhadap kinerja perusahaan. Menurut Almajali (2012) bahwa current ratio berpengaruh terhadap kinerja keuangan dengan hubungan arah karena kenaikan likuiditas akan menaikkan kinerja perusahaan. Menurut Mahardhika, dkk (2016) dan Ngendakumana (2016) menyatakan bahwa current ratio yang tinggi akan meningkatkan ROA dan akan baik pula kinerja keuangannya. Semakin tinggi current ratio maka akan semakin menurunkan kinerja keuangan suatu perusahaan menurut Nadem, dkk (2014).

\section{METODE}

\section{Populasi dan sampel}

Pilihan peneliti dimana pengumpulan data diambil dari BEI tahun 2017-2019 dengan cara kuantitatif serta jenis deskriptif. Sebanyak 72 Perusahaan Sektor Industri Dasar dan Kimia yang terdaftar di BEI menjadi populasi dalam riset ini. Jumlah data sebanyak 117 dengan 3 tahun pengamatan.

\section{HASIL DAN PEMBAHASAN}

\section{Statistik deskriptif}

Descriptive statistic bagi setiap variable yang mana variable bebas yaitu EVA, CS, TATO, CR dan variable dependen yaitu Kinerja Keuangan. Jumlah data observasi sebanyak 117 dengan 3 tahun pengamatan. Data statistic dari seluruh data statistic variable yang dipergunakan dalam pembahasan Tabel 1.

Berdasarkan data Tabel 1 diketahui total sample, nilai terbesar, nilai terkecil, nilai rata-rata dan standard deviation adalah: Economic Value Added (EVA) memiliki nilai terendah -58845500 oleh Waskita Beton Precast Tbk tahun 2017, dan sebaliknya Economic Value Added (EVA) mendapatkan nilai tertinggi 1410841 oleh Semen 
Indonesia (Persero) Tbk tahun 2017 dengan mean -578399 serta standart deviasi sebesar 5452020.

Tabel 1. Statistik deskriptif

\begin{tabular}{lrrrrr}
\hline & N & Min. & \multicolumn{1}{c}{ Max. } & \multicolumn{1}{c}{ Mean } & $\begin{array}{r}\text { Standard } \\
\text { Deviation }\end{array}$ \\
\hline EVA(X1) & 117 & -58845500 & 1410841 & -578399 & 5452020 \\
DER(X2) & 117 & .0994 & 8.3003 & 1.063300 & 1.0763488 \\
TATO(X3) & 117 & .2871 & 3.8608 & .967606 & .7073596 \\
CR(X4) & 117 & .6805 & 21.7045 & 2.603213 & 2.6296963 \\
ROA(Y) & 117 & .0004 & .2575 & .055035 & .0457682 \\
Valid N (listwise) & 117 & & & & \\
\hline
\end{tabular}

Sumber: Data diolah, 2020

Selanjutnya, capital structure (DER) memiliki nilai terendah sebesar 0.0994 oleh Emdeki Utama tahun 2018, dan sebaliknya DER memiliki nilai tertinggi sebesar 8.3003 oleh Aneka Gas Industri (Tbk) Tahun 2017 dengan mean 1.063300 serta standart deviasi sebesar 1.0763488. Total assets turnover (TATO) memiliki nilai terendah sebasar 0.2871 oleh Aneka Gas Industri Tbk Tahun 2017, dan sebaliknya TATO memiliki nilai tertinggi sebesar 3.8608 oleh Tembaga Mulia Semanan Tbk Tahun 2018 dengan mean 0.967606 serta standart deviasi sebesar 0.7073596. Current ratio $(\mathrm{CR})$ mempunyai nilai terendah sebesar 0.6805 oleh Waskita Beton Precast Tbk Tahun 2018, dan sebaliknya CR memiliki nilai tertinggi sebesar 21.7045 oleh Duta Pertiwi Nusantara Tbk tahun 2019 dengan mean 2.603213 serta standart deviasi 2.6296963. Kinerja keuangan (ROA) memiliki nilai terendah sebesar 0.0004 oleh Kirana Megatara Tbk tahun 2018, dan sebaliknya ROA memiliki nilai tertinggi sebasar 0.2575 oleh Mark Dynamics Indonesia Tbk tahun 2018 dengan mean 0.055035 serta standart deviasi sebesar 0.0457682 .

\section{Hasil uji asumsi klasik}

\section{Uji normalitas}

Berdasarkan Gambar 1 menunjukkan bahwa sebagian besar ada terdapat dalam kurva serta berbentuk simetris. Dalam hal ini, berdasarkan Gambar 1 diketahui bahwa berdistribusi normal.

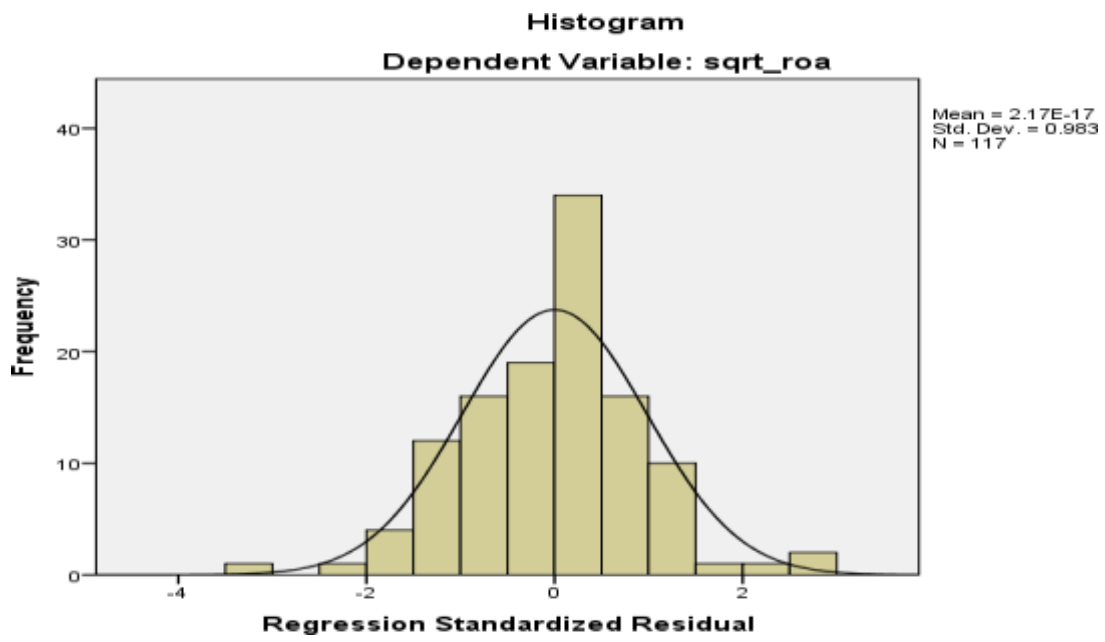

Gambar 1. Histogram 
Selain itu pada Gambar 2 menunjukkan bahwa semua titik mengikuti garis tengah. Jadi, bisa dikatakan data ini terdistribusi dengan normal. Hasilnya sesuai dengan kriteria, sehingga data berdistribusi normal.

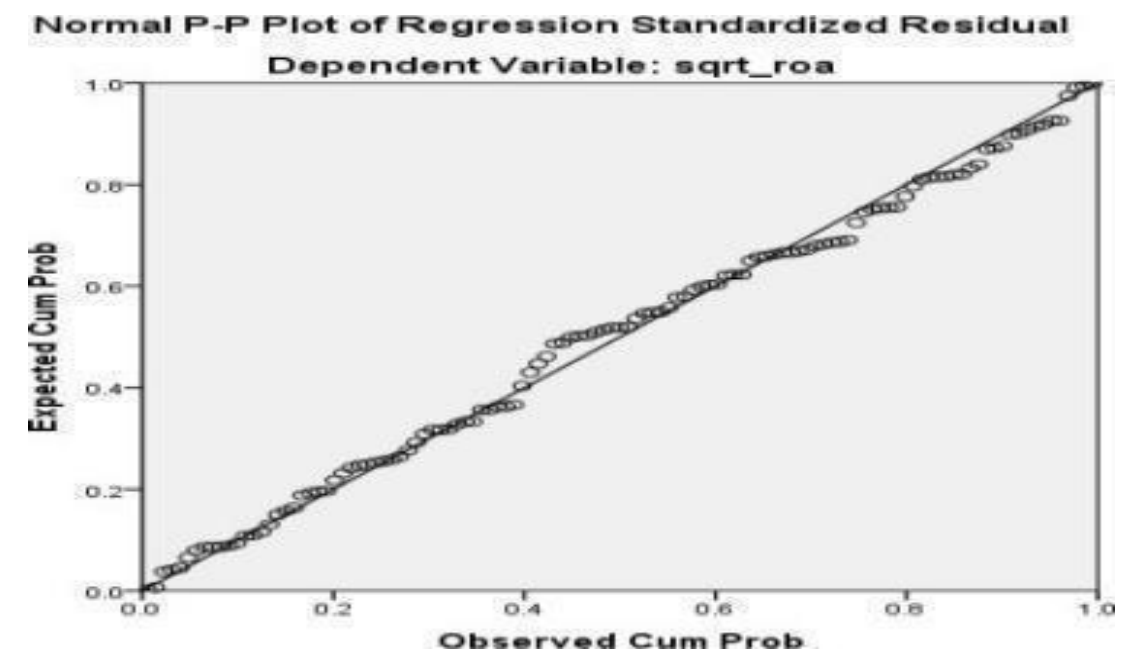

Gambar 2. Normal P-P Plot Regression

Selanjutnya dilakukan uji Kolmogorov-Smirnov $(K-S)$ pada Tabel 2 menunjukkan bahwa nilai Z 0.636 dan Asympy.Sig (2-tailed) 0.813 yang menunjukkan data berdistribusi normal.

Tabel 2. Uji Kolmogorov-Smirnov $(K-S)$

\begin{tabular}{lc}
\hline & $\begin{array}{c}\text { Unstandardized } \\
\text { residual }\end{array}$ \\
\hline Kolmogorov-Smirnov Z & .636 \\
Asymp.Sig.(2-tailed) & .813
\end{tabular}

Sumber: Data diolah, 2020

Pengujian Tabel 3, mengatakan bahwa tidak terjadi multikolonieritras karena diketahui bahwa tolerance variable economic value added (EVA), capital structure, total assets turnover dan current ratio melebihi 0.10 dan nilai VIF tidak lebih dari 10.

Tabel 3. Uji multikolinearitas

\begin{tabular}{llcc}
\hline \multirow{2}{*}{ Model } & \multicolumn{2}{c}{ Collinearity Statistics } \\
\cline { 3 - 4 } & (Const) & & VIF \\
\hline 1 & Tolerance & \\
& sqrt_eva & .992 & 1.008 \\
& sqrt_der & .654 & 1.528 \\
sqrt_tato & .973 & 1.027 \\
& sqrt_cr & .663 & 1.509 \\
\hline
\end{tabular}

Sumber: Data diolah, 2020

Selanjutnya, dari keterangan Tabel 4 karena Durbin watson senilai 1,352 maka, DW $=-2<1.352<2$ maka tidak terjadinya autokorelasi. 
Tabel 4. Uji autokorelasi

\begin{tabular}{lc}
\hline Model & Durbin-Watson \\
\hline $\mathbf{1}$ & 1.352
\end{tabular}

Sumber: Data diolah, 2020

\section{Uji heteroskedastisitas}

Hasil signifikan dari tabel uji park dibawah, diketahui tidak terjadi heterokedastisitas dikarenakan semua variable memiliki nilai $>0.05$.

Tabel 5. Uji park

\begin{tabular}{llccccc}
\hline \multirow{2}{*}{ Model } & \multicolumn{2}{c}{$\begin{array}{c}\text { Unstandardized } \\
\text { Coefficients }\end{array}$} & $\begin{array}{c}\text { Standardized } \\
\text { Coefficients }\end{array}$ & \multirow{2}{*}{ t } & Sig. \\
\cline { 2 - 5 } & B & Std. Error & Beta & & \\
\hline 1 & (Constant) & -8.591 & .531 & & -16.169 & .000 \\
& EVA & .025 & .042 & .055 & .590 & .556 \\
& DER & .257 & .228 & .113 & 1.130 & .261 \\
TATO & .289 & .327 & .083 & .883 & .379 \\
& CR & .069 & .092 & .074 & .752 & .454 \\
\hline
\end{tabular}

a. Dependent Variable: LN_RES

Sumber: Data diolah, 2020

Berdasarkan Tabel 6 menunjukkan bahwa jumlah hasil constant yaitu 0.177 maksudnya jika nilai EVA, DER, TATO dan CR dianggap konstan, jadi ROA tahun 2017-2019 adalah 0.177. EVA berpengaruh positif terhadap nilai coefisient sebesar 0,004 maksudnya setiap bertambahnya Rp 1 EVA akan menaikkan ROA sebesar Rp 0,004. DER berpengaruh negatif terhadap nilai coefisient sebesar $-0,080$ maksudnya setiap berkurangnya Rp 1 DER akan mengurangi ROA sebesar Rp -0,080.

Tabel 6. Hasil uji regresi linier berganda

\begin{tabular}{lcc}
\hline \multirow{2}{*}{ Model } & \multicolumn{2}{c}{ Unstandardized coefficients } \\
\cline { 2 - 3 } & B & Std.Error \\
\hline (Const) & .177 & .052 \\
SQRT_EVA & .004 & .013 \\
SQRT_DER & -.080 & .024 \\
SQRT_TATO & .112 & .027 \\
SQRT_CR & .001 & .016 \\
\hline
\end{tabular}

Sumber : Data diolah, 2020

SQRT_ROA= 0.177 + 0.004 SQRT_EVA - 0.080 SQRT_DER + 0.112

SQRT_TATO + 0.01 SQRT_CR

Selanjutnya variabel TATO berpengaruh positif terhadap nilai coefisient sebesar 0,112 maksudnya setiap bertambahnya Rp 1 TATO akan menaikkan ROA sebesar Rp 0,112. CR berpengaruh positif terhadap nilai coefisient sebesar 0.001 maksudnya setiap bertambahnya Rp1 CR akan menaikkan ROA sebesar Rp0,001. 
Tabel 7. Koefisiensi determinasi $\left(\mathrm{R}^{2}\right)$

\begin{tabular}{cccccc}
\hline Model & R & R Square & $\begin{array}{c}\text { Adjusted } \\
\text { RSquare }\end{array}$ & $\begin{array}{c}\text { Std.Error of } \\
\text { theEstimate }\end{array}$ & $\begin{array}{c}\text { Durbin- } \\
\text { Watson }\end{array}$ \\
\hline 1 & .46 & .220 & .192 & .085655 & 1.470
\end{tabular}

Sumber: Data diolah, 2020

Dari Tabel 7, jumlah coefisient determinasi dapat ditentukan oleh Adjusted $R$ Square $\left(R^{2}\right)$ sebesar 0,192, maksudnya $19.2 \%$ variable terikat (ROA) mampu diterapkan terhadap variable bebas diantaranya EVA, DER, TATO, CR dan selebihnya sebesar $80.8 \%$ digunakan oleh variable lain selain variable yang digunakan contohnya seperti ROE, investasi, tingkat harga saham dan deviden.

Tabel 8. Pengujian hipotesis secara simultan (uji signifikan F)

\begin{tabular}{rlccccc}
\hline Model & $\begin{array}{c}\text { Sum of } \\
\text { Squares }\end{array}$ & \multicolumn{1}{c}{ df } & $\begin{array}{c}\text { Mean } \\
\text { Square }\end{array}$ & F & Sig. \\
\hline \multirow{3}{*}{1} & Regression & .232 & 4 & .058 & 7.89 & $.000^{\mathrm{b}}$ \\
& Residual & .822 & 112 & .007 & & \\
& Total & 1.053 & 116 & & & \\
\hline
\end{tabular}

Sumber: Data diolah, 2020

Dari hasil uji diatas menyimpulkan bahwa F-hitung sebesar 7.896 dengan jumlah Sig-nya 0,000 sementara F-tabel diketahui 2,68, dapat disimpulkan bahwa F-hitung > Ftabelialah 7.896>2,68 maka kesimpulannya adalah $\mathrm{H}_{0}$ ditolak Ha diterima, maksudnya maksudnya mengalami signifikan terhadap ROA pada perusahaan yang digunakan.

Tabel 9. Pengujian hipotesis secara parsial (uji signifikan t)

\begin{tabular}{llll}
\hline \multicolumn{2}{c}{ Model } & t & Sig. \\
\hline $\mathbf{1}$ & (Constant) & 3.385 & .001 \\
& SQRT_EVA & .324 & .747 \\
& SQRT_DER & -3.420 & .001 \\
& SQRT_TATO & 4.203 & .000 \\
& SQRT_CR & .063 & .950 \\
\hline
\end{tabular}

Sumber : Data diolah, 2020

Tabel 9 menunjukkan bahwa pengujian dari Tabel $t$ bisa memberikan penjelasan bahwa variabel bebas secara parsial sebagai berikut: Variable EVA memiliki signifikan sebesar 0,747 dengan t-hitung 0.324 dan jumlah t-tabel adalah 1,98118 dan ketentuan signifikan sebesar 0,05 kesimpulannya bahwa nilai t-hitung<t-tabel $(0.324<1,98118)$ dan nilai signifikannya $>0,05$ adalah $\mathrm{Ha}$ ditolak, dan $\mathrm{H}_{0}$ diterima. Maka kesimpulannya adalah EVA tidak ada berpengaruh dan tidak signifikan dengan kinerja keuangan di perusahaan sektor industri dasar \& kimia pada tahun 2017-2019. 
Variable DER memiliki signifikan sebesar 0,001 dengan t-hitung-3,420 dan jumlah t-tabel adalah 1,98118 dan ketentuan signifikan sebesar 0,05 kesimpulannya bahwa t-hitung $<$ t-tabel $(-3,420<1,98118)$ dan nilai signifikannya $<0,05$ adalah $\mathrm{Ha}$ ditolak dan $\mathrm{H}_{0}$ diterima. Maka kesimpulannya adalah DER tidak memberikan pengaruh signifikan terhadap kinerja keuangan di perusahaan sektor industri dasar \& kimia pada tahun 2017-2019. Variable TATO memiliki signifikan sebesar 0,000 dengan t-hitung 4.203 dan jumlah t-tabel adalah1,98118 dan ketentuan signifikan sebesar 0,05 kesimpulannya bahwa t-hitung $>$ t-tabel $(4.203>1,98118)$ dan nilai signifikannya $<0,05$ adalah Ha diterima dan HO ditolak. Maka kesimpulannya adalah TATO memberikan pengaruh signifikan terhadap kinerja keuangan di perusahaan sektor industri dasar \& kimia pada Tahun 2017-2019.

Variable CR memiliki signifikan sebesar 0,950 dengan t-hitung 0.063 dan jumlah ttabel adalah 1,98118 dan ketentuan signifikan sebesar 0,05 kesimpulannya bahwa thitung<t-tabel $(0.063<1,98118)$ dan nilai signifikannya $>0,05$ adalah Ha ditolak dan $\mathrm{H}_{0}$ diterima. Maka kesimpulannya adalah CR tidak memberi pengaruh dan tidak signifikan terhadap kinerja keuangan di perusahaan sektor industri dasar \& kimia pada tahun 20172019.

\section{Pengaruh economic value added (EVA) terhadap kinerja keuangan}

Dari penjelasan diatas dapat disimpulkan bahwa EVA tidak memberi pengaruh signifikan dengan ROA di perusahaan sektor industri dasar \& kimia pada tahun 20172019. Berarti apabila EVA mengalami kenaikan atau penurunan itu tidak ada pengaruhnya terhadap return on assets. Dalam teori Ismail (2011) ini sangat berbeda, semakin tinggi EVA akan memberikan dampak positif dan penambahan nilai, begitu juga apabila EVA rendah maka memberikan dampak negatif terhadap perusahaan yang menyimpulkan bahwa tingginya nilai EVA menjadi ketentuan baiknya nilai perusahaan. Penelitian Ratih, Moch. Dzulkirom, dan Muhammad Saifi (2014) bahwa hasilnya sangat berbeda, kesimpulannya bahwa perhitungan nilai EVA sangat berpengaruh signifikan terhadap return on assets. Tinggi nilai EVA, baik juga nilai perusahaannya.

\section{Pengaruh capital structure terhadap kinerja keuangan}

Kesimpulan dari hal diatas bahwa DER tidak memberi pengaruh signifikan pada Kinerja Keuangan digunakan Perusahaan tersebut. Dari kesimpulan diatas maka hal ini berbeda dengan teori Kusumajaya (2011) bahwa Capital Structure memberikan pengaruh positif dan signifikan. Maka tinggi nilai DER akan baik juga return on assets, begitu sebaliknya apabila DER dalam suatu perusahaan rendah, maka return on assets nya tidak baik. Hasil diatas memiliki kesamaan dengan penelitian yang dilakukan Fadilah (2011) dengan menggunakan data panel, bahwa rasio leverage yang ada memberi pengaruh signifikan pada kinerja keuangan perusahaan dilihat berdasarkan ROA, ROE dan PER.

\section{Pengaruh total assets turnover (TATO) terhadap kinerja keuangan}

Dari hasil diatas bahwa TATO bersignifikan terhadap variable ROA diperusahaan Sektor Industri Dasar \& Kimia pada tahun 2017-2019. Hal diatas sama dengan Teori Rachmat Rizky Muchlis (2017) mengatakan kalau total assets turnover terhadap return on assets sangat signifikan menyimpulkan semakin besar berputar nya asset maka sangat berpengaruh terhadap pendapatan laba yang didapatkan dari pengelolaan asset 
yang dimiliki. Ini memiliki kesamaan penelitian yang dilakukan Anggeresia (2018) bahwasannya TATO secara parsial memberi signifikan yang positif terhadap ROA karena perusahaan memanfaatkan semua asset yang untuk kegiatan operasionalnya yang dapat meningkatkan laba.

\section{Pengaruh current ratio (CR) terhadap kinerja keuangan}

Dari penjelasan uji diatas disimpulkan CR tidak ada berpengaruh dan tidak signifikan terhadap kinerja keuangan yang digunakan perusahaan tersebut. Hal diatas berbeda dengan teori Almajali,et al (2012) bahwa current ratio berpengaruh terhadap kinerja keuangan dengan hubungan searah karena kenaikan likuiditas akan menaikkan kinerja perusahaan. Hal diatas berbeda dengan pendapat Peneliti Desy Anggareni (2015) dalam penelitiannya yang menyatakan bahwa berdasarkan uji simultan variabel tersebut dengan ukuran sebuah perusahaan memberikan signifikan terhadap kinerja perusahaan.

\section{KESIMPULAN DAN SARAN}

\section{Kesimpulan}

Mcnurut penjelasan dapat disimpulkan menjadi beberapa keputusan antara Iain: secara partial bahwa economic value added, debt equity ratio, dan current ratio tidak ada berpengaruh dan tidak signifikan dan total assets turnover bcrpengaruh signifikan terhadap kinerja keuangan di perusahaan sektor lndustri dasar dan kimia pada tahun 2017-2019. Selanjutnya secara simultan disimpulkan bahwa economic value added, debt equity ratio, total assets turnover dan current ratio berpengaruh signifikan terhadap kinerja keuangan di perusahaan sektor industri dasar dan kimia pada Tahun 2017- 2019.

\section{Saran}

Menurut hasil diatas yang dapat disarankan oleh pengkaji adalah: 1) Bagi Peneliti Selanjutnya adalah untuk menjadikan referensi bagi peneliti selanjutnya yang berjudul sama yakni "pengaruh economic value added, capital structure, total assets turnover, dan current ratio terhadap kinerja keuangan" agar dapat memudahkan pembuatan tugas akhir kuliah 2) Bagi UNPRI adalah untuk dapat dijadikan bahan studi karya ilmiah di Universitas Prima Indonesia (UNPRI) dalam judul pengaruh economic value added, capital structure, total assets turnover, dan current ratio terhadap kinerja keuangan, 3) Bagi pemerintah dapat berguna untuk sebagai pedoman bagi pihak peusahaan dalam peningkatan kinerja di suatu perusahaan agar dapat meningkatkan laba.

\section{DAFTAR PUSTAKA}

Alpi, M. F., \& Gunawan, A. (2018). Pengaruh current ratio dan total assets turnover terhadap return on assets pada perusahaan plastik dan kemasan. Jurnal Riset Akuntansi Aksioma, 17(2), 001-036. https://doi.org/10.29303/aksioma. v17i2.43

Anggraeni, D. (2015). Pengaruh current ratio, quick ratio, debt to equity ratio dan ukuran perusahaan terhadap kinerja perusahaan. Jurnal Akuntansi dan Keuangan FE Universitas Budi Luhur, 4(2), 41-60 
Budiarti, H. U. (2019). Pengaruh CR, TATO dan DER terhadap kinerja keuangan perusahaan food and beverages di BEI. Jurnal Ilmu dan Riset Manajemen, 8(6), $1-15$

BEI, B.E. (2017-2019). Financial accounting and annual report. Diakses dalam http://www.idx.co.id, Tanggal 3 Januari 2019, Pukul 12.30 WIB

Deines, P. A. (2010). Introduction to accounting an integrated approach. Tim Vertovec: New York.

Dewi, A. K.(2015). Analisis struktur modal terhadap kinerja keuangan perusahaan sektor . Jurnal Manajemen dan Organisasi, VI(2), 134-148

Dewi, M. (2017). Penilaian kinerja keuangan perusahaan dengan menggunakan metode EVA (economic value added) (studi kasus pada PT. Krakatau Steel Tbk Periode 2012-2016). Jurnal Manajemen dan Keuangan, 6(1), 648-659. Retrieved from https://ejurnalunsam.id/index.php/jmk/article/view/212

Falianty, T.A. (2012). Kajian ekonomi dan keuangan. Kajian Ekonomi dan Keuangan (KEK), 16(1), 17-36.

Ginting, W. A. (2018). Analisis pengaruh current ratio, working capital turnover, dan total asset turnover terhadap return on asset. Jurnal Ilmiah, 15(2), 163-172. Retrieved from http://journal.stieamm.ac.id/index.php/valid/article/view/73

Gunawan, M. A. (2018). Pengaruh current ratio dan total assets turnover terhadap return on assets pada perusahaan plastik dan kemasan. Jurnal Riset Akuntansi, 17(2), 001 - 036.

Herman Supardi, H. S. (2016). Pengaruh current ratio, debt to asset ratio,total assets turnover . Jurnal Ilmiah Akuntansi Fakultas Ekonomi, 2(2), 16-27.

Kasmir. (2012). Analisis laporan keuangan. PT. Raja Grafindo Persada: Jakarta

Dhani, PI., \& AA, Gde Satia Utama. (2017). Pengaruh pertumbuhan perusahaan, struktur modal, dan profitabilitas terhadap nilai. Jurnal Riset Akuntansi dan Bisnis Airlangga, 2(1), 135-148

Wardani. A.K., \& Farida R.D. (2015). Analisis struktur modal terhadap kinerja keuangan perusahaan sektor utama yang terdaftar di Indeks LQ45 Bursa Efek Indonesia. Jurnal Manajemen dan Organisasi, 6(2), 134-148 